\title{
Education development employing latest free space optical research papers for undergraduate communication engineering students in class and examination
}

\section{Ahmed Abd El Aziz, Abeer Badawi}

Ahmed Abd El Aziz, Abeer Badawi, "Education development employing latest free space optical research papers for undergraduate communication engineering students in class and examination," Proc. SPIE 11143, Fifteenth Conference on Education and Training in Optics and Photonics: ETOP 2019, 1114338 (2 July 2019); doi: 10.1117/12.2523450 


\title{
Education development employing latest free space optical research papers for undergraduate communication engineering students in class and examination
}

\author{
Ahmed Abd El Aziz, Abeer Badawi \\ Photonic Research Laboratory, Arab Academy for Science, Technology and Maritime Transport, \\ College of Engineering and Technology, Alexandria, Egypt
}

\begin{abstract}
In this paper, we introduce advanced undergraduate communication engineering students to the newest research papers in the optical communications field. An elective course named 'Selected Topics in Communications' offered to final year students in Electronics and Communication department, faculty of Engineering, Arab Academy for Science and Technology (AAST), Egypt, focuses on free space optics (FSO). The course objective is to equip students with the necessary theoretical models and the practical knowledge of free FSO from the most recent research. The course studies the current FSO capabilities, constraints, challenges and applications both indoors and outdoors in atmospheric, space and underwater channels. The main prerequisite to the course is digital communications due to the dependence on optical technology on high speed transmission and different modulation techniques in order to achieve best performance. In lectures, we define what a paper is and identify their different types. We explain the difference between conferences and journals, the reviewing process and their requirements. Lectures include how to read and write a technical research paper. Such lectures are to familiarize students with the construction of a paper, how is it organized how to scan for certain information and read results. In tutorials, students practice on different research papers and extract required information according to prepared question sheets. At least $25 \%$ of the course marks are dedicated to research papers. Lecturers pick an unknown paper for examination. On the other, students are required to perform a paper presentation after choosing a recent paper on a certain topic.
\end{abstract}

Keywords: Free space optics, optical communications, research papers,

\section{INTRODUCTION}

Optical has become one of the fastest growing communication fields as a result of the tremendous growth of internet capacity and the large increase in traffic demands. The necessity of different optical communication systems and networks for managing the high-speed data flows has recently emerged. In the past few years, great achievements and significant breakthroughs have been made in the free space optical (FSO) communications field ${ }^{1}$. FSO has attracted interests for many applications both indoors and outdoors. To be able to keep-up with the rapid evolving technology, communications engineers are required to gain at least the basic knowledge and the fundamentals of the optical field. They should be prepared to gather the full potential and challenges of optical communications and be able to compete in its groundbreaking development and rapid innovation. Unfortunately, most educational entities and engineering programs in Egypt offer less focus on optical compared to other fields of communications. Those limited programs who do offer optical studies concentrate on photonic devices and/or optical fibers technologies. However, the free space optical communication (also termed as optical wireless) is rarely studied which consequently created an obvious gap in the optical educational process. For that reason, the 'Selected Topics in Communications' course has chosen to focus on FSO for the past two years in order to fill such gap in the electronics and communications engineering education and to expose students to the rapidly changing and promising field.

In spite of the internet rapidly gaining a strong grip as a fast source for gaining information, reading research papers/articles, still remains the most precise and meticulous approach of acquiring new information. It has become vital for students and 
researchers to read research papers from scientific conferences or journals. Not only to keep abreast of progress in the field of specialty concerned but also to be aware of the current trends, approaches and techniques ${ }^{2}$. Research papers are essential in the learning process of any field, but are particularly significant in engineering due to the rapid development in technologies. Unfortunately, undergraduate courses offered in the field of engineering are widely dominated by the traditional passive lecture format with very limited to no access or knowledge from the students to research problems and research papers. It is very important for students who are looking to choose their final year graduation project, their career or to carry out practical experiments to read scientific literature. This would help students/researchers to understand and gather enough information on what has been already discovered and the research questions that remain unanswered for designing their research projects.

In order to maximize the students learning skills, lecturers of the 'Selected Topics in Communications' course, have included the art of reading a research paper in the course, besides the traditional passive lecture format. In this course, students learn how to read and extract specific information from a research paper/article and are challenged to confirm such learning outcome through exam. Students are also taught how to present a scientific paper in class within limited time duration followed by question and answer session. Using a flipped classroom method, students present a recent high quality published research paper within the FSO field role-playing the author as a speaker in a conference. These approaches would help the students to gain or improve their presentation, research and communication skills. This paper presents the 'Selected Topics in Communications' course description, the teaching methods used and how each method has been implemented.

\section{COURSE DESCRIPTION}

The 'Selected Topics in Communications' is taught as an elective course in the Electronics and Communications Engineering program at the Arab Academy for Science, Technology and Maritime Transport (AASTMT). The objective of this course is to teach a new evolving topic in communication engineering every few years by different lecturers. Since the fall semester of 2017, the course is designed to teach free space optical communication (i.e. optical wireless communication) in order to overcome the gap in the optical educational process. Students in the final year of their degree (i.e. $9^{\text {th }}$ and $10^{\text {th }}$ semester) are advised to take the course as one of their five elective courses if they are interested in the field. The curriculum is updated to match the current state in research.

The course lasts for 16 weeks; each week contains a 2-hour lecture and a 2-hour tutorial session. For the successful completion of the course, students are required to have an overall score of at least 60 marks out of 100 available. The College of Engineering grading system is listed below in Table 1. Those marks are collected throughout the course period in the form of exams (regular and research paper), presentations (flipped classroom), oral marks and a final exam.

Unfortunately, the Electronics and Communications Engineering program at AASTMT does not yet offer core optical-related courses. However, two elective optical-related courses are taught in the program, namely 'Photonic Devices' and 'Optical Communications'. The 'Photonic Devices' focuses on the main devices that are used in the optical communications field. It studies the different types of optical sources, photodetectors and other up-to-date photonic devices that can perform most of the functions required for all-optical networks and photonic signal processing.

On the other hand, the 'Optical Communications' concentrates on light propagation and data transmission through fibers (i.e. wired optical communications). Students study the different types of fibers and their structures, modes of light propagation, factors affecting data transmission through fibers and optical fibers applications. Although there is a great interest in free space optical communication applications in recent years both indoors and outdoors worldwide, students in the program did not have the chance to study such important field. Consequently, 'Selected Topics in Communications' course is designed to cover that missing part in the optical educational process. Figure 1 shows the position of the 'Selected Topics in Communications' course main contents (i.e. studied topics) shaded in grey within the structure of the optical educational process. 
Table 1. College of Engineering grading system.

\begin{tabular}{|l|l|l|}
\hline Grade & Points & Percentage \\
\hline A+ & 4 & $97 \%-<=100 \%$ \\
\hline A & 3.83 & $93 \%-<97 \%$ \\
\hline A- & 3.7 & $89 \%-<93 \%$ \\
\hline B+ & 3.3 & $84 \%-<89 \%$ \\
\hline B & 3 & $80 \%-<84 \%$ \\
\hline B- & 2.7 & $76 \%-<80 \%$ \\
\hline C + & 2.3 & $73 \%-<76 \%$ \\
\hline C & 2 & $70 \%-<73 \%$ \\
\hline C- & 1.7 & $67 \%-<70 \%$ \\
\hline D+ & 1.3 & $63 \%-<67 \%$ \\
\hline D & 1 & $60 \%-<63 \%$ \\
\hline F & Zero & $<60 \%$ \\
\hline
\end{tabular}

In the beginning of this course, students are introduced to quick historical and background information on optical communications due to the fact that it is an elective course and they may not be aware nor had any access to related studies. The advantages, spectrum bands, differences and challenges of the evolving technology compared to other communication techniques are explained. Before studying the fundamentals of FSO, students are required to learn briefly about optical sources and photodetectors. This is for students to differentiate between the requirements of different applications.

The focus of the course curriculum is then directed to FSO and the main topics covered are:

- Indoors FSO

- Main indoors example: LiFi

- LiFi genesis and $\mathrm{WiFi}$ limitations

- LiFi principle of operation and standards

○ LiFi applications

○ LiFi challenges and constraints

- Visible light communications (VLC) model

- Outdoors FSO

- Atmospheric channel

- Fog attenuation model

- Rain attenuation model

- Humidity attenuation model

- Space channel

- Inter-satellite link (ISL) 


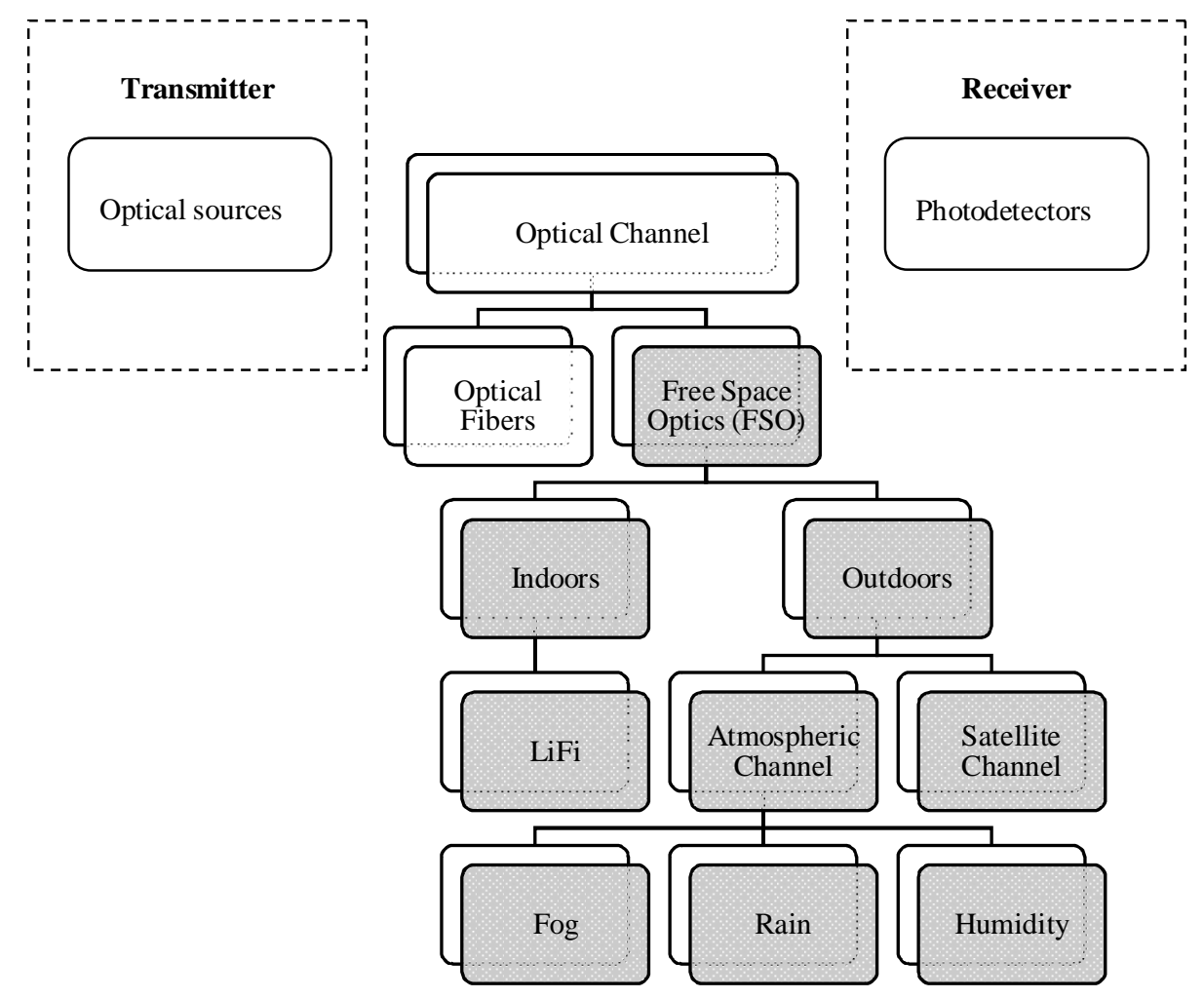

Figure 1. 'Selected Topics in Communications' course main contents within the structure of the optical educational process.

\section{COURSE TEACHING METHODS}

Four different teaching methods are employed in this course. Lectures offer the theoretical information in traditional ways. They are essential in delivering the concepts of free space optical communications. In lectures, the models, requirements, constraints and challenges of indoors and outdoors FSO are explained. They cover the key factors affecting optical transmission in different free space channels. Unfortunately, limited interaction or participation from students is required; however, they are encouraged to ask questions and criticize ideas during the lectures part of the course.

Students are prompted to work in small groups or pairs (depending on the number of students registered for the course) on a set of actual engineering problems in the field of FSO. According to the theoretical and mathematical models of the different FSO channels (both indoors and outdoors) studied, students execute the most appropriate mathematical solution and present their results to their peers. This teaching method aims to improve their teamwork skills, expose them to actual optical transmission challenges and enhance their problem-solving ability.

The other two teaching methods used in this course allow students to embrace awareness of the field's scientific publications and provide them with undergraduate research capabilities ${ }^{3,4}$. The third method challenges students to extract specific information from research papers. On the other hand, students are required to present a scientific FSO publication; roleplaying the author in a flipped classroom setting as the final teaching method. These methods are the focus of this paper and are separately discussed in the following section. All parts of these teaching methods in class fits together like puzzle pieces. Teaching recently published research papers complete this puzzle by giving students clear expectations, preparing them for scientific research and strengthening their reading and writing skills in academic way. 


\section{FSO RESEARCH PAPER INFORMATION EXTRACTION AND PRESENTION}

There is a huge impact of undergraduate research on the overall education of engineering students. Students who are involved in research activities during their undergraduate studies have shown better understanding of the field, improved communication skills and higher GPAs. Research gives the undergraduate students the opportunity to face up-to-date and open-ended research problems 5 . Unfortunately, undergraduate research is not common in the engineering field in general. As a result, those students' knowledge is outdated and they are not well prepared for their postgraduate level of studies in the optical field later on. Accordingly, this course has taken the initiative to expose students to recent FSO research papers and teach them how to read, extract specific information and present published research papers/articles.

In both lectures and tutorials, students learn the scientific research publication process. They get to know how peer-reviewing takes place and the differences between conference and journal publications. Lecturers highlight and stress on the scientific research ethical aspect, integrity and originality. They are also encouraged to use the university's library resources in order to access the most up-to-date FSO research papers. Students learn how to analyze and criticize the obtained results and question the papers' authenticity and similarities. These studies help to put undergraduate students on the right research track.

In the beginning, students study the main structure of a scientific paper in order to easily determine where to find required information. They learn the most common design of original research papers with abstract, introduction, methods, results, and discussion (IMRAD). The main purpose of each section is clearly identified in order to speed up the paper scanning process and to easily extract data. Few recent published papers in the FSO field have been used as examples to familiarize students with different research points, problem statements and approaches. Examples also help students distinguish between well and badly written scientific papers.

For about 4-5 weeks, students exercise to extract specific required information from recent FSO research papers. Each week in tutorial sessions, a set of questions regarding a new FSO published research is distributed together with the paper among the class members. These questions are intended to cover different kinds of information from all over the paper. Questions can include the contribution, problem statement, earlier research in literature, methodology, transmission parameters, graphs or paper results and findings. Students within class are asked to extract answers from the paper first individually and then in groups. Before the end of the session, students would have learned how to gather the required information. These sessions are repeated weekly with a different paper and a corresponding question sheet. The improvement in students reading and information fetching skills is apparent every session. After students are trained on such method, they are examined with questions on a different research paper in order to guarantee that they have achieved such skills. The fact that students are not studying for an exam and are already prepared gives a fun edge and raises their motivation to obtain the full mark available which is accounted for $15 \%$ of the course entire grade. The effort required by the lecturer/instructor is not only to choose clear, recent and appropriate papers for students in the FSO field, but also to study in minute details and prepare a variety of questions beforehand to cover the significant points for each paper.

In order to ensure that students have fully understood the concepts of scientific papers and to improve their research reading and presentation skills, a flipped classroom setting is introduced in this course, where a student role-play the as the author of a published paper. Students are asked to choose a recent high quality paper in a course related topic (i.e. free space optics) in order to present it; role-playing the actual speaker in a conference. Similar to most conferences, the speaker is allowed a 1015 minute presentation followed by another 10-5 minutes, respectively for discussions and questions. The overall presentation session for each paper lasts for about 20 minutes. Students present their assigned paper in tutorial sessions in front of all class members and tutors in order to experience a conference like atmosphere. This presentation is accounted a respectful $10 \%$ of the course entire grade with extra bonus marks offered for creativity or outstanding delivery. A picture for the students and lecturers after one of these presentation sessions is displayed below in Figure 2. Audience also benefit by learning new information about the main topic of the paper. 
After choosing their papers, students are given few weeks to prepare before delivering their presentation. This provides the students with the necessary time to gather enough basic background information for understanding their assigned papers. They are asked to read, fully understand and critically analyze their assigned papers in terms of methodology and achieved results aiming to identify its strong and weak aspects. Each student is advised to defend his/her paper by stressing on its strengths and justifying its weaknesses. Throughout the preparation phase, students are encouraged to look up the references of their assigned papers. During this period, students can consult their lecturers for any missing background information or clarifications regarding any unknown concepts, provided that enough effort have been done to research their questions beforehand. Lecturers also encourage students to directly contact the papers' authors for further clarifications or required information. A summary for the main points can be prepared by students to guide and help them deliver their presentation in a concise and scientifically accurate manner. Some of the topics covered in paper presentations by the students include:

- $\quad \mathrm{LiFi}$

- Visible light communication (VLC) in biomedical

- Flash light VLC

- Vehicle-to-vehicle VLC

- LED-to-LED communication

- Impact of fog on free space optics (FSO)

- Impact of rain on FSO

- Impact of humidity on FSO

- Inter-satellite link (ISL)

- Underwater FSO

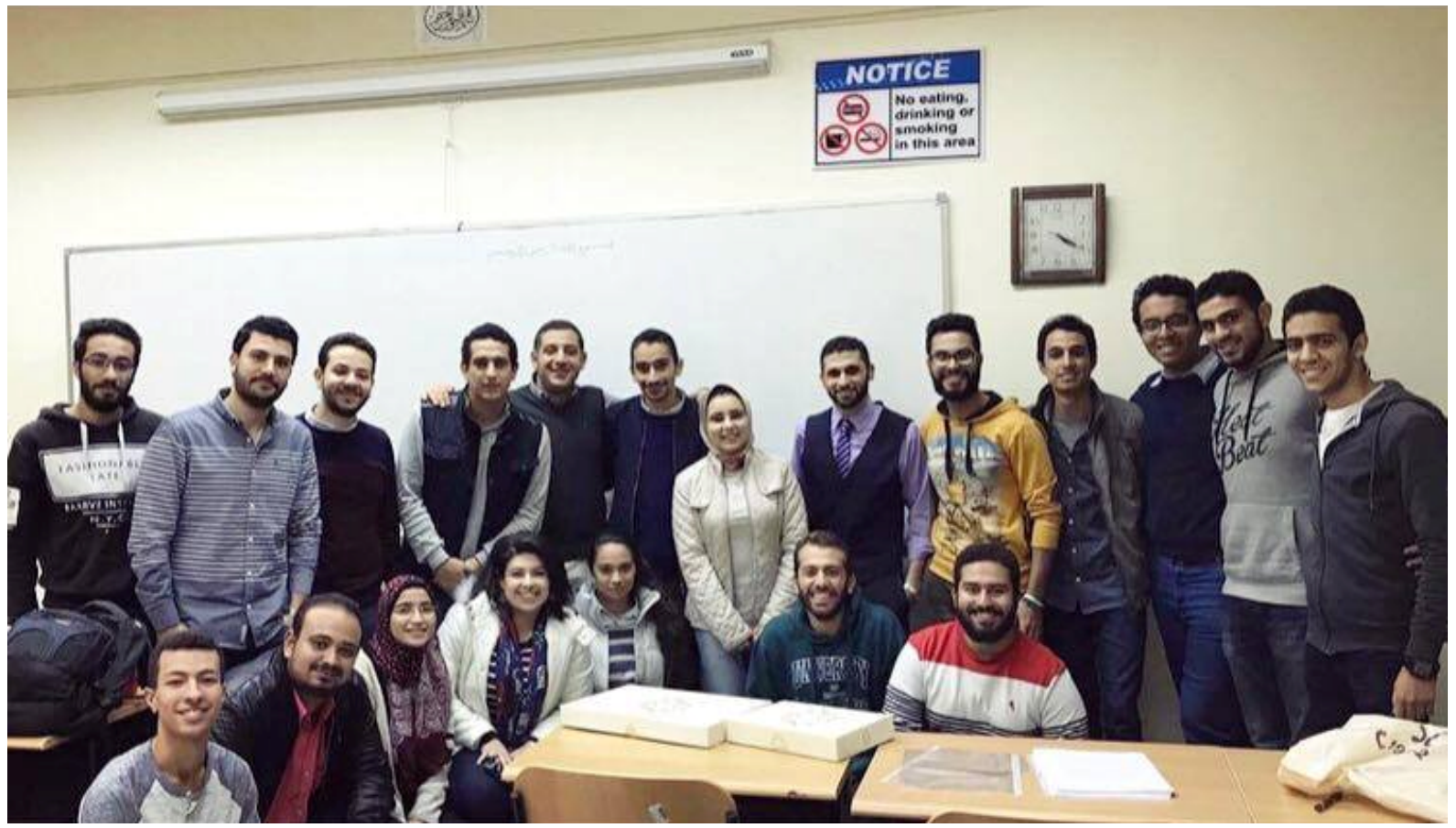

Figure 2. A picture for the students and lecturers after one of the paper presentation sessions. 


\section{CONCLUSION}

The 'Selected Topics in Communications' is taught as an elective course within the Electronics and Communications engineering program at the Arab Academy for Science, Technology and Maritime Transport. The course aims to study the free space optical communication key fundamentals, constraints and applications both indoors and outdoors. To maximize the students' achieved skills in this course, the lecturers employed a variety of teaching methods. Besides the traditional passive lectures and problem-solving tutorials, students are introduced to the field's scientific publications and provide them with undergraduate research capabilities. The course identifies how a research paper is structured and the difference in conference and journal publications. Students not only learn how to read, find information and critically analyze the results published in a scientific paper, but they also engage with class activities and improve their communication, teamwork and presentation skills. In this course, students are trained to extract specific information from many free space optical (FSO) research papers. In order to round up the students' achieved skill, they are examined with an unknown scientific paper. On the other hand, students are assigned a recent FSO published paper to prepare and present; role playing the author/speaker in a conference like environment. At least $25 \%$ of the course entire grade is dedicated to the employed undergraduate research methods. The increased interest in the course and FSO communication field as well as the students' positive feedback justifies the successful undergraduate research methods utilized in course.

\section{REFERENCES}

1. Elgala H. Indoor Optical Wireless Communication : Potential and State-of-the-Art. IEEE Commun Mag. 2011;(September):56-62.

2. Subramanyam, R. V., Sudha and Nageswara Rao Siddhartha, "Art of reading a journal article: Methodically and effectively", J Oral Maxillofac Pathol. 2013 Jan-Apr; 17(1): 65-70. doi: 10.4103/0973-029X.110733

3. Wang, Z., Geng, M., Cheng, X., Jiang, Z., "Study of research-based teaching mode in the course of Geometric Optics and Optical Instruments," Proc. SPIE 10452, (2017)

4. Adams, R., Chen, L. R., "Engaging college physics students with photonics research," Proc. SPIE 10452, (2017).

5. Bishay PL. Introducing undergraduate research in Numerical Analysis of Engineering Systems course. Int J Mech Eng Educ. 2018;46(4):345-361. doi:10.1177/0306419018778043 